\title{
Controlled trial of hydroxocobalamin and riboflavine in Nigerian ataxic neuropathy
}

\author{
B. O. OSUNTOKUN, M. J. S. LANGMAN, J. WILSON $\mathbf{1}$, AND A. AlADETOYINBO
}

From the Department of Neurology and Psychiatry, University College Hospital, Ibadan, Nigeria; University Department of Medicine, General Hospital, Nottingham; M.R.C. Clinical Genetics Research Unit, Institute of Child Health and Institute of Neurology, London; and the Department of Neurology and Psychiatry, University College Hospital, Ibadan, Nigeria

SUMMARY The results are presented of a double-blind therapeutic trial of hydroxocobalamin and riboflavine in Nigerian patients suffering from a degenerative neuropathy. Although no benefit from either vitamin was demonstrated, this may reflect the inadequacy of the dosages used. The results are discussed in relation to the hypothesis that dietary cyanide and cyanogens are responsible, at least in part, for the occurrence of this disease in a malnourished population.

There is increasing evidence that a degenerative neurological disease known as 'tropical ataxia' or 'tropical ataxic neuropathy' in Nigeria may be caused, at least partly, by the consumption of cassava, the staple diet of large numbers of people living in tropical and sub-tropical areas.

A recent epidemiological study of the disease in Western Nigeria has shown that the prevalence of the syndrome varies with the amount of cassava eaten (Osuntokun, Monekosso, and Wilson, 1969) but it is also recognized that there is co-existing malnourishment in other respects, notably in the intake of the sulphur-containing amino acids, and perhaps of riboflavine.

It is well known that the tuber of cassava (Manioc utilissima) contains large amounts of the cyanogenetic glycoside linamarin in its outer integument and, although the indigenous methods of food preparation eliminate most of this compound from the edible product, significant quantities of cyanogenetic material, and perhaps free cyanide, persist and are ingested.

It has, therefore, been suggested that this degenerative neurological disease may represent a form of chronic cyanide toxicity which may be related to Leber's disease (Wilson, 1963, 1965), subacute combined degeneration of the cord (Wilson and Langman, 1966), and tobacco amblyopia (Smith, 1961).

Significantly higher concentrations of thiocyanate,

${ }^{1}$ Address for reprints: Dr. J. Wilson, M.R.C. Clinical Genetics Research Unit, National Hospital, Queen Square, London, W.C.1. an important detoxication product of cyanide, have been found in the serum of patients with tropical ataxia compared with that of control individuals (Monekosso and Wilson, 1966; Osuntokun, 1968; Osuntokun, Monekosso, and Wilson, 1969). Changes in the distribution of cyanide-displaceable proteinbound vitamin $\mathbf{B}_{12}$ in plasma have also been demonstrated (Monekosso and Wilson, 1966; Osuntokun, 1968; Osuntokun et al., 1969), and the findings are consistent with the suggestion that cyanide or cyanogen ingestion in patients is excessive.

Since hydroxocobalamin has a strong affinity for cyanide in vitro, and has a demonstrable protective effect in acute cyanide poisoning in vivo, it was decided to conduct a therapeutic trial of this agent in a group of Nigerian patients suffering from the disease. Riboflavine was also included in the trial in view of the suggestion that deficiency of this vitamin may be a contributory factor.

\section{PATIENTS}

The 80 patients treated all showed the clinical features of the ataxic neuropathy as previously described (Osuntokun, 1968, 1969). They were newly diagnosed and, as far as could be ascertained, had not been treated (conventionally) previously. Those whose disease was so advanced that they were bedridden were not included in the trial because it was considered that irreversible neuropathological damage was established, and was not amenable to treatment. The patients were all seen at a District Research Centre maintained by the Wellcome Trust 
at Epe, a large town 70 miles south-east of Ibadan in an area where tropical neuropathy is common. Fifteen of the patients were also investigated in the Neurological Unit at University College Hospital Ibadan, for periods not exceeding one week.

\section{METHODS}

Identically-appearing ampoules containing, respectively, $1,000 \mu \mathrm{g}$ hydroxocobalamin, $5 \mathrm{mg}$ riboflavine dyed with amaranth, and $1 \mu \mathrm{g}$ cyanocobalamin (as control) were prescribed by reference to a pre-arranged schedule prepared by one of us (M.J.S.L.). Treatment was rando nized with the restriction that each group of six patients was divided equally between the three treatments. The patients themselves and their examiner (B.O.O.) were unaware of any differences of treatment, and we conclude that the trial was effectively double-blind. The ampoules were flown to Nigeria in a cold-storage compartment and stored throughout the trial at $4^{\circ} \mathrm{C}$. Injections were given at weekly intervals for the first 12 weeks of treatment, and thereafter, because of the practical difficulties of giving weekly injections, at two-weekly intervals for a further 24 weeks.

Clinical assessment was completed before and after the trial according to a scheme modified from Alexander (1951) in which neurological signs and symptoms were scored numerically. Improvement or deterioration during the trial was represented by a reduction or an increase in the score respectively. The patients' practical disabilities were also assessed at the beginning and at the end of the trial by the method suggested by Miller, Newell, and Ridley (1961).

Plasma thiocyanate and cyanide concentrations were estimated by the method of Aldridge (1945), cyanide being separated from thiocyanate by an aeration technique described by Boxer and Rickards (1951). Serum vitamin $B_{12}$ concentrations were estimated in duplicate, on aliquots of sera with and without the addition of cyanide to the buffer used in extracting vitamin $B_{12}$ bound to serum proteins, as described by Smith (1961) and Wilson and Matthews (1966). It has been suggested that differences in 'extractability' thus demonstrated are the consequence of cyanide exposure.

\section{RESULTS}

Eighty patients were seen initially and treatment started, and all, except one treated with riboflavine, were examined at the end of the trial. Of the 79 patients assessed at the beginning and at the end of the trial 26 received vitamin $B_{12}, 26$ were given riboflavine, and 27 received the control preparation. But 12 (six treated with riboflavine, one with hydroxocobalamin, and five with the control preparation) failed to attend the clinic regularly. Details of clinical comparability of all these patients are given in Table 1 and show that there were no substantial differences in respect of age, the proportions of men and women, or their initial neurological score. The patients'
TABLE 1

COMPARABILITY OF PATIENTS GIVEN THE THREE TREATMENTS

\begin{tabular}{lccc}
\hline & \multicolumn{3}{c}{ Treatment group } \\
\cline { 2 - 4 } & Hydroxocobalamine & Riboflavine & Control \\
\hline Men & 15 & 16 & 15 \\
Women & 11 & 10 & 12 \\
$\begin{array}{l}\text { Mean age (yr) } \\
\text { Mean initial } \\
\text { neurological } \\
\text { score }\end{array}$ & 45.1 & 46.7 & 47.1 \\
\hline
\end{tabular}

ages proved hard to determine, since few knew their precise dates of birth; as a consequence 31 of the $\mathbf{8 0}$ patients' dates of birth were recorded simply in 0 multiples of five. In Table 2 the mean results of $\nRightarrow$ serum vitamin $B_{12}$ measurements with and without $\vec{\circ}$ cyanide extraction are given. None of the patients showed evidence of deficiency of the vitamin. The high mean concentrations found were similar to those found previously in patients with the disease.

\section{TABLE 2}

MEAN SERUM VITAMIN $B_{12}$ CONCENTRATIONS IN VARIOU O TREATMENT GROUPS AT BEGINNING OF TRIAL, WITH AND $O$ WITHOUT CYANIDE IN EXTRACTING BUFFER

\begin{tabular}{lccccc}
\hline \multirow{2}{*}{ Treatment group } & \multicolumn{4}{c}{ Mean $B_{12}$ concentrations $(\mathrm{pg} / \mathrm{ml}$.) with S.E.M. } \\
\cline { 2 - 6 } & No. & $\begin{array}{c}\text { (A) With } \\
\text { cyanide }\end{array}$ & $\begin{array}{c}\text { (B) Without } \\
\text { cyanide }\end{array}$ & (B) $\times 10$ (A) \\
\hline Hydroxocobalamin & 23 & $1903 \pm 204$ & $1173 \pm 154$ & 58.5 \\
Riboflavine & 22 & $1927 \pm 260$ & $1223 \pm 194$ & 59.6 \\
Placebo & 22 & $1604 \pm 110$ & $941 \pm 141$ & 57.9 \\
\hline
\end{tabular}

Assessment by disability scale added no useful information to that obtained from the neurological examination scores, and therefore in Table 3 the changes in these alone have been given. Comparisons between initial and final results were made by cal-

TABLE 3

OVERALL RESULTS OF NEUROLOGICAL ASSESSMENT SCORES

\begin{tabular}{lc}
\hline \multicolumn{1}{c}{ Treatment } & $\begin{array}{c}\text { Mean percentage change } \\
\text { in neurological scores }\end{array}$ \\
\hline Hydroxocobalamin & $+9 \cdot 6^{*}$ \\
Riboflavine & $-8 \cdot 1$ \\
Placebo & $-5 \cdot 2$ \\
\hline
\end{tabular}

Individual final scores were expressed as percentages of initial scores and the means of these individual figures were calculated.

Positive changes indicate deterioration. Negative changes represent improvement.

*The omission of one figure of $+210.0 \%$ reduces this figure to $+1.6 \%$. 
culating the percentage change in total neurological score for each patient-(for example, initial score $=50$, final score $=60$, therefore percentage change $=20 \%$ in deterioration). Table 3 shows the mean percentage change in neurological scores, but in making statistical comparisons a non-parametric ranking test (Mann Whitney $U$ test) was applied: the differences found between hydroxocobalamin and control, and riboflavine and control were statistically insignificant $(P=0.1$ and $P=0.4$ respectively). To ensure that minor improvements in individuals with less severe neurological disease were not being masked by poor results in those with severe disease, the findings were considered separately for those with less severe disease (initial score less than 100) and severe disease (initial score 100 or more). The results, which are given in Table 4, show no evidence of such a masking effect. Separate consideration of the results obtained in the irregular attenders at the Clinic did not suggest that their neurological changes differed in any important respect from those found in the remainder. At the end of the trial patients were asked whether they considered that they had benefited from the treatment and Table 5 shows the results of these subjective assessments.

\section{TABLE 4}

MEAN NUMERICAL ASSESSMENT SCORES IN PATIENTS SUBDIVIDED ACCORDING TO SEVERITY OF INITIAL INVOLVEMENT

\begin{tabular}{lcccc}
\hline \multicolumn{1}{c}{ Treatment } & Initial & Final & Change & $\begin{array}{c}\text { Number } \\
\text { treated }\end{array}$ \\
\hline & a. & \multicolumn{2}{c}{ Initial score less than 100} & \\
Hydroxocobalamin & 63.3 & 79.6 & +16.3 & 12 \\
Riboflavine & 59.5 & 52.3 & $-7 \cdot 2$ & 11 \\
Placebo & 67.2 & 64.1 & -3.1 & 11 \\
& & & & \\
& b. & Initial score & 100 or more & \\
Hydroxocobalamin & 174.3 & 177.9 & +3.6 & 14 \\
Riboflavine & 175.3 & 167.0 & -8.3 & 15 \\
Placebo & 180.6 & 162.2 & -18.4 & 16 \\
\hline
\end{tabular}

TABLE 5

SUBJECTIVE CHANGES IN THERAPEUTIC TRIAL OF HYDROXOCOBALAMIN AND RIBOFLAVINE

\begin{tabular}{lcccc}
\hline \multicolumn{1}{c}{ Treatment } & Better & No change & Worse & Total \\
\hline Hydroxocobalamin & 13 & 9 & 4 & 26 \\
Riboflavine & 8 & 16 & 1 & $25 *$ \\
Placebo & 9 & 13 & 5 & 27 \\
\hline & 30 & 38 & 10 & 78 \\
\hline
\end{tabular}

*In one individual no assessment was made of subjective change, and one further individual defaulted from the trial.

A greater proportion of individuals treated with hydroxocobalamin thought that they had benefited from treatment than did those given riboflavine or the control preparation but the difference was not statistically significant $\left(\chi^{2}=2.20 P=0.34\right)$ in comparing all improved with all 'no change' or 'worse'.

Plasma thiocyanate concentrations were determined at the start of the trial and at the mid-point and are shown in Table 6 for patients in each of the three treatment groups. The concentrations tended to fall irrespective of the treatment given and there were no significant differences between them. Plasma cyanide concentrations could be determined in only 28 of the patients at the start of the trial because of the problems posed by making the estimations in the District Centre. There was a correlation between plasma thiocyanate and cyanide concentration $(r=0.60 P<0.001)$ with a tendency for increasing variability as both values rose.

\section{TABLE 6}

MEAN THIOCYANATE CONCENTRATIONS BEFORE AND DURING TRIAL IN INDIVIDUALS IN WHOM PAIRED MEASUREMENTS WERE MADE

\begin{tabular}{lrrc}
\hline Treatment group & \multicolumn{3}{c}{ Mean concentrations $(\mu-$ mole $/ 100 \mathrm{ml}$. $)$} \\
& \multicolumn{1}{c}{ with S.E.M. } \\
\cline { 2 - 4 } & Before & During & Number \\
\hline Hydroxocobalamin & $10.7 \pm 0.9$ & $9.0 \pm 0.7$ & 26 \\
Riboflavine & $12.0 \pm 1.0$ & $10.6 \pm 0.9$ & 21 \\
Placebo & $9.9 \pm 0.6$ & $7.9 \pm 0.7$ & 25 \\
\hline
\end{tabular}

\section{DISCUSSION}

The present study leaves no doubt that, under the conditions of the trial, there was no significant objective benefit attributable to treatment with either hydroxocobalamin or riboflavine, although, as judged subjectively, there was some evidence favouring hydroxocobalamin.

The organization of such a trial as this presented formidable practical difficulties in a rural Nigerian setting, but we are satisfied that the double-blind scheme adopted for the trial was effective and that the patients allocated the three different treatments were comparable with each other.

The biochemical features of the patients were similar to those seen in other series (Monekosso and Wilson, 1966; Osuntokun, 1968) and almost certainly reflect the high cyanide or cyanogen exposure experienced by this population, which consumes large quantities of cassava. As in other series, the high serum levels of vitamin $B_{12}$ remain unexplained. The slight fall in mean plasma thiocyanate concentrations in the three treatment groups seen during the trial may be a reflection of the longitudinal variation of cyanide or cyanogen intake according 
to the season rather than of any non-specific treatment effects.

Previous therapeutic trials using B vitamin preparations have yielded conflicting results. Spillane (1947) was disappointed with the results of thiamine administration in wartime cases of tropical neuropathy that he studied, and Pallister (1940) and McLaren (1960) noted the absence of improvement with the administration of vitamin B complex in their cases. Others (Wright, 1928; Nicholls, 1935) claimed some improvement with yeast or Marmite, and assumed that this was due to the content of $\mathbf{B}$ vitamins. However, other nutritional factors present-for instance, cystine-may have been effective. The same may be true of the trial reported by Monekosso, Annan, and Ashby (1964) in which controls as well as patients treated with thiamine improved, for both groups were hospital in-patients and therefore probably benefited from non-specific dietary improvements.

Clark (1936) claimed that Oluwole successfully treated Nigerian children with tropical amblyopia by reducing the amount of cassava in the diet. These observations have not been deliberately reproduced subsequently, but Moore (1937) treated a small group of Nigerians suffering from the amblyopic syndrome with intravenous thiosulphate solution, as an antidote to cyanogen derived from cassava, without apparent benefit.

The present trial was designed to test the hypothesis of cyanogen intoxication by including further hydroxocobalamin as a potent antagonist of cyanide. The lack of therapeutic success does not necessarily invalidate the hypothesis, for the absence of clearcut improvement could be due among other things to inadequate dosage, both of hydroxocobalamin and of riboflavine.

While hydroxocobalamin binds cyanide very quickly, weight for weight it is relatively inefficient, a reflection of its very high molecular weight. In addition, it must be emphasized that the patients in this trial continued to subsist on their normal diet with its inevitably high cyanogen content. It is improbable that well-established dietary habits can be substantially modified in this community but a further trial using much higher doses of hydroxocobalamin, for comparison with large doses of vitamin B complex and cystine, as a further cyanide detoxicant, is now in progress because it is not considered that this initial negative therapeutic result invalidates the hypothesis of cyanide intoxication.

This study was supported by a grant from the Wellcome Trust. We are grateful to Dr. R. J. Wrighton and his assistants at Glaxo Laboratories for their help in organizing the preparation of the ampoules of vitamins used. These were donated by Glaxo Laboratories.

\section{REFERENCES}

Aldridge, W. N. (1945). The estimation of micro quantities of cyanide and thiocyanate. Analyst, 70, 474-475.

Alexander, L. (1951). New concept of critical steps in course of chronic debilitating neurologic disease in evaluation of therapeutic response; longitudinal study of multiple sclerosis by quantitative evaluation of neurologic involvement and disability. Arch. Neurol. Psychiat. (Chic.), 66, 253-271.

Boxer, G. E., and Rickards, J. C. (1950). Chemical determination of vitamin $B_{12}$. II. The quantitative isola- $\because$ tion and colorimetric determination of millimicrogram $\overline{\bar{\omega}}$ quantities of cyanide. Arch. Biochem., 30, 372-381.

Clark, A. (1936). Report on the effects of certain poisons contained in food-plants of West Africa upon health of native races. J. trop. Med. Hyg., 39, 269-276 and 285-295.

McLaren, D. S. (1960). Malnutrition and eye disease in Tanganyika. Proc. Nutr. Soc., 19, 89-91.

Miller, H., Newell, D. J., and Ridley, A. (1961). Multiple sclerosis. Treatment of acute exacerbations with corticotrophin (A.C.T.H.). Lancet, 2, 1120-1122.

Monekosso, G. L., Annan, W. G. T., and Ashby, P. H. $\vec{\omega}$ (1964). Therapeutic effect of vitamin B complex on an ataxic syndrome in Western Nigeria. Trans. roy. Soc. trop. Med. Hyg., 58, 432-436.

Monekosso, G. L., and Wilson, J. (1966). Plasma thio- $\omega$ cyanate and vitamin $B_{12}$ in Nigerian patients with $\omega$ degenerative neurological disease. Lancet, 1, 1062 8 1064.

Moore, D. G. F. (1937). Retrobulbar neuritis cum avita. minosia (followed by post partial optic atrophy, no․ 윽 shown to be of pellagrinous nature. Its serious inct dence and its need for general investigation). Wert Afr. med. J., 9, 35-40.

Nicholls, L. (1935). Nerve and cord degeneration referab\& to vitamin-A deficiency. Indian med. Gaz., 70, 550-55送

Osuntokun, B. O. (1968). An ataxic neuropathy in Nigeria. A clinical, biochemical and electrophysiologica study. Brain, 91, 215-248.

Osuntokun, B. O. (1969). Chronic cyanide intoxication and a degenerative neuropathy in Nigeria. Ph.D. Thesis, University of Ibadan.

Osuntokun, B. O., Monekosso, G. L., and Wilson, J. (1969). Relationship of a degenerative tropical neuropathy to diet. Report of a field survey. Brit. med. J., 1, 응 547-550.

Pallister, R. A. (1940). Ataxic paraplegia occurring amongst Chinese in Malaya. Trans. roy. Soc. trop. Med. $\overrightarrow{0}$ Hyg., 34, 203-211

Smith, A. D. M. (1961). Retrobulbar neuritis in Addisonian pernicious anaemia. Lancet, 1, 1001-1002.

Spillane, J. D. (1947). Nutritional Disorders of the Nervous System. Livingstone: Edinburgh.

Wilson, J. (1963). Leber's hereditary optic atrophy-some clinical and aetiological considerations. Brain, 86, б 347-362.

Wilson, J. (1965). Leber's hereditary optic atrophy: a possible defect of cyanide metabolism. Clin. Sci., 29, 505-515.

Wilson, J., and Langman, M. J. S. (1966). Relation of subacute combined degeneration of the cord to vitamin $B_{12}$ deficiency. Nature (Lond.), 212, 787-789.

Wilson, J., and Matthews, D. M. (1966). Metabolic inter- 음 relationships between cyanide, thiocyanate and vitamin $B_{12}$ in smokers and non-smokers. Clin. Sci., 31, ช 1-7.

Wright, E. J. (1928). Disease due to $A$ and $B$ avitaminosis in Sierra Leone. West Afr. med.J., 2, 127-130. 